Epidemiology and Psychiatric

Sciences

\section{cambridge.org/eps}

\section{Presentation of the \\ Editorials}

Cite this article: Bonati M (2020).

Transitioning youth to adult age also through health services. Epidemiology and Psychiatric Sciences 29, e88, 1-2. https://doi.org/10.1017/ S2045796019000842

Received: 8 November 2019

Accepted: 14 November 2019

Key words:

Adolescence; chronic care; health service research; interdisciplinary relations

Author for correspondence:

Maurizio Bonati, E-mail: maurizio.bonati@ marionegri.it (c) The Author(s) 2020. This is an Open Access article, distributed under the terms of the Creative Commons Attribution licence (http:// creativecommons.org/licenses/by/4.0/), which permits unrestricted re-use, distribution, and reproduction in any medium, provided the original work is properly cited.

\section{CAMBRIDGE} UNIVERSITY PRESS

\title{
Transitioning youth to adult age also through health services
}

Maurizio Bonati (D)

Laboratory for Mother and Child Health, Department of Public Health, Istituto di Ricerche Farmacologiche Mario Negri IRCCS, Via Negri M. 2, 20156 Milan, Italy

The developmental transition epoch of late adolescence to early adulthood is a time of evolution (Chan et al., 2019). Transition is not synonymous with transfer. Transition is an active action, collegiate and participated. Transfer is a passive action - a suffered one. Transition is the process of preparation for the transfer between paediatric and adult age, and it can also happen for the passage between health services. Transition includes the initial planning, the transfer itself and the support provided throughout, including the support provided in adult care (Schor, 2015). Transition should be a purposeful and planned process provided as a core component of developmentally appropriate health care for all young people with chronic diseases during adolescence and young adulthood (Tuchman et al., 2008; Hepburn et al., 2015). Unfortunately, only about half of adolescents and young adults with chronic diseases receive any preparation for this transfer of healthcare (Reiss et al., 2005), despite the fact that significant determinants influencing gaps in care for adolescents with complex chronic conditions transitioning to adulthood have been identified (Goossens et al., 2016). Transition to adult services is a risky period that can lead to reduced engagement with health care, and preventing adolescents from becoming lost in the transfer is one of the challenges (Willis and McDonagh, 2017; Nguyen et al., 2018). These challenges are compounded by both multiple, concurrent developmental transitions that may be underway (i.e., shift to independent living, postsecondary education or the workforce and personal and peer relationships/social networks) and a lack of continuity of care into adult services (Suris and Akre, 2015). To complicate things further is the WHO's definition of young people (10-24 years old), increasingly used to reflect the protracted nature of transition as well as the biopsychosocial stages of development (Schor, 2015; Ki-moon, 2016). This, in turn, raises the issue of whether the challenges of transition are more closely related to adolescent and young adult development rather than to the professional handover of care (McManus et al., 2015; Leyenaar et al., 2017).

Despite the increased interest over the past decade, this issue is addressed by only a few countries (USA, UK and Canada) and is contemplated for specific chronic conditions (diabetes and spina bifida) and with interventions of low documented evidence (Mora et al., 2019). Although there has been abundant literature outlining agreed principles of good transitional care, also incorporated into guidelines, the effectiveness has so far been scarce (Nagra et al., 2015).

Studies evaluating chronic conditions identified various factors involved in a successful transition, including the importance of continuity and relationships with familiar health professionals and better information and involvement in care management. Studies exploring this issue show that there are often differences between user, parent and clinician perspectives (Reiss et al., 2005). The transition to adult services often results in poor patient and parent satisfaction and loss to follow-up for young adults with chronic diseases. (Leyenaar et al., 2017; Chu et al., 2015; Suris et al., 2017). The experiences of young people, parents and clinicians suggest joint-working as a frequent, shared need, given the reported lack of two-way communication as a major impediment to a successful transition process. Moreover, flexibility concerning transition-age thresholds is seen as a key component of good transition by both patients and parents. Studies evaluating parents' perspectives show that parents would like to be more involved in their child care as the child transitions to an adult service, and feel left out or feel they have no one with whom to discuss their worries about their children (Leyenaar et al., 2017). This specific need could be related to the different cultural philosophies between child and adult systems, with the first being more family-oriented, inclusive and holistic than adult services, and the second being focused more exclusively on the individual (Davis et al., 2014).

Unmet needs for youths moving from paediatric to adult services have been identified across disciplines (i.e., neurology, psychiatry, gastroenterology, rheumatology, pneumology) underling that differences in managing the care and in-service organisation, both between and within countries, accentuate the problems (Benchimol et al., 2011; Srivastava et al., 2012; Stagi et al., 2015; Andrade et al., 2017; Mori, 2018). Moreover, chronic disorders belong to a set of comorbidities that can also affect the transition between health services (Van Cleave et al., 2013). Thus, although certain programmes have shown positive results within one or a few centres, or in interventional research, their feasibility in daily practice and their adoption at 
national levels have yet to be defined and reached. Efforts are therefore needed at different levels and should involve all pertinent figures, by relevance and responsibility, to ensure the seamless continuity of care. Supporting youth transitioning into adulthood through integrated and coordinated care is a pressing issue for many countries globally as it impacts research, clinical practice and policy. Thus, determining strategies and appropriate practices to optimise services for transitioning youth and young adults with chronic needs are a priority for healthcare systems.

The following essays offer constructive reflections on the transfer and/or transition of young people with mental disorders, in particular on the currently available evidence for the two most investigated conditions (Attention deficit hyperactivity disorder ADHD and Autism spectrum disorder ASD) in the mental health field. These two disorders differ from chronic conditions for their complexity, comorbidities, multimodal therapy and need for a broad range of services and/or support (Bennett et al., 2018; Wilens et al., 2018). They are disorders in which the grade of impairment may also affect the event of becoming autonomous to some extent, although this event is the goal of transition of all youths, both healthy and ill, and the expectation of all parents. These are reflections that cannot be exempted from consideration of the social and economic circumstances, the local health-care system and the cultural level of the community where the transition must happen (i.e., where it will be planned, sustained and accompanied) (Eilenberg et al., 2019). Thus, transition can also be a determinant of health inequalities within and between countries where patients and parents are too often left alone and can become lost in transition. Consequently, permanent monitoring and implementation actions at local and national levels should be set up involving all the care providers. In addition, future research should focus on providing clear evidence on the effectiveness of transition interventions in all countries.

In the two following essays a few considerations and references are repeated. It would have been possible to edit the text in order to avoid duplication. Instead, the choice was to maintain the repetitions to emphasise the relationship of the two disorders, often as comorbidities, but also to underline possible common answers to these common needs. This, of course, is a reflection to be verified also in many other circumstances.

Acknowledgement. None.

Financial support. None.

Conflict of interest. None.

\section{References}

Benchimol EI, Fortinsky KJ, Gozdyra P, Van den Heuvel M, Van Limbergen J and Griffiths AM (2011) Epidemiology of pediatric inflammatory bowel disease: a systematic review of international trends. Inflammatory Bowel Diseases 17, 423-439.

Bennett AE, Miller JS, Stollon N, Prasad R and Blum NJ (2018) Autism spectrum disorder and transition-aged youth. Current Psychiatry Reports 20, 103, Review.

Andrade DM, Bassett AS, Bercovici E, Borlot F, Bui E, Camfield P, Clozza GQ, Cohen E, Gofine T, Graves L, Greenaway J, Guttman B, GuttmanSlater M, Hassan A, Henze M, Kaufman M, Lawless B, Lee H, Lindzon L, Lomax LB, McAndrews MP, Menna-Dack D, Minassian BA, Mulligan J, Nabbout R, Nejm T, Secco M, Sellers L, Shapiro M, Slegr M, Smith R, Szatmari P, Tao L, Vogt A, Whiting S and Carter Snead O 3rd (2017) Epilepsy: Transition from pediatric to adult care. Recommendations of the Ontario epilepsy implementation task force. Epilepsia 58, 1502-1517.
Chan V, Moore J, Derenne J and Fuchs DC (2019) Transitional age youth and college mental health. Child and Adolescent Psychiatric Clinic of North America 28, 363-375.

Chu PY, Maslow GR, von Isenburg M and Chung RJ (2015) Systematic review of the impact of transition interventions for adolescents with chronic illness on transfer from pediatric to adult healthcare. Journal of Pediatric Nursing 30, e19-e27.

Davis AM, Brown RF, Taylor JL, Epstein RA and McPheeters ML (2014) Transition care for children with special health care needs. Pediatrics $\mathbf{1 3 4}$ 900-908.

Eilenberg JS, Paff M, Harrison AJ and Long KA (2019) Disparities based on race, ethnicity, and socioeconomic status over the transition to adulthood among adolescents and young adults on the autism spectrum: a systematic review. Current Psychiatry Reports 21, 32, Review.

Goossens E, Bovijn L, Gewillig M, Budts W and Moons P (2016) Predictors of care gaps in adolescents with complex chronic condition transitioning to adulthood. Pediatrics 137, e20152413, Review.

Hepburn CM, Cohen E, Bhawra J, Weiser N, Hayeems RZ and Guttmann A (2015) Health system strategies supporting transition to adult care. Archives of Disease in Childhood 100, 559-564.

Ki-moon B (2016) Sustainability-engaging future generations now. Lancet 387, 2356-2358.

Leyenaar JK, O'Brien ER, Leslie LK, Lindenauer PK and Mangione-Smith RM (2017) Families' priorities regarding hospital-to-home transitions for children with medical complexity. Pediatrics 139, e20161581.

McManus M, White P, Barbour A, Downing B, Hawkins K, Quion N, Tuchman L, Cooley WC and McAllister JW (2015) Pediatric to adult transition: a quality improvement model for primary care. Journal of Adolescent Health 56, 73-78.

Mora MA, Saarijärvi M, Moons P, Sparud-Lundin C, Bratt EL and Goossens E (2019) The scope of research on transfer and transition in young persons with chronic conditions. Journal of Adolescent Health 65, 581-589.

Mori M (2018) Pediatric rheumatic diseases: a review regarding the improvement of long-term prognosis and the transition to adults. Immunological Medicine 41, 2-5.

Nagra A, McGinnity PM, Davis N and Salmon AP (2015) Implementing transition: ready steady go. Archives of Disease in Childhood Education and Practice Edition 100, 313-320.

Nguyen T, Stewart D and Gorter JW (2018) Looking back to move forward: reflections and lessons learned about transitions to adulthood for youth with disabilities. Child Care Health and Devopment 44, 83-88.

Reiss JG, Gibson RW and Walker LR (2005) Health care transition: youth, family, and provider perspectives. Pediatrics 115, 112-120.

Schor EL (2015) Transition: changing old habits. Pediatrics 135, 958-960.

Srivastava SA, Elkin SL and Bilton D (2012) The transition of adolescents with chronic respiratory illness to adult care. Paediatric Respiratory Reviews 13, 230-235.

Stagi P, Galeotti S, Mimmi S, Starace F and Castagnini AC (2015) Continuity of care from child and adolescent to adult mental health services: evidence from a regional survey in Northern Italy. European Child \& Adolescent Psychiatry 24, 1535-1541.

Suris JC and Akre C (2015) Key elements for, and indicators of, a successful transition: an international Delphi study. Journal of Adolescent Health 56, 612-618.

Suris JC, Larbre JP, Hofer M, Hauschild M, Barrense-Dias Y, Berchtold A and Akre C (2017) Transition from paediatric to adult care: what makes it easier for parents? Child Care Health and Development 43, 152-155.

Tuchman LK, Slap GB and Britto MT (2008) Transition to adult care: experiences and expectations of adolescents with a chronic illness. Child Care Health and Development 34, 557-563.

Van Cleave JH, Trotta RL, Lysaght S, Steis MR, Lorenz RA and Naylor MD (2013) Comorbidities in the context of care transitions. ANS Advances in Nursing Science 36, E1-E13.

Wilens TE, Isenberg BM, Kaminski TA, Lyons RM and Quintero J (2018) Attention-Deficit/Hyperactivity disorder and transitional aged youth. Current Psychiatry Reports 20, 100, Review.

Willis ER and McDonagh JE (2017) Transition from children's to adults' services for young people using health or social care services (NICE Guideline NG43). Archives of Disease in Childhood Education and Practice Edition 103, 253-256 